\title{
HOLDING FAMILIAR
}

Bruno Gabriel Dassie Baptista, João Paulo Ângelo Vasconcelos

Universidade do Oeste Paulista- UNOESTE, Presidente Prudente, SP. e-mail: brunodassie@hotmail.com, j.paulo.vasconcelos@uol.com.br

\section{RESUMO}

Este trabalho teve por objetivo avaliar, à luz da doutrina jurídica, como uma holding familiar influencia os rumos de um processo divisão de cotas em empresas como forma de antecipação e segurança hereditária. Por questões metodológicas, este estudo vai se debruçar sobre o setor jurídico brasileiro, que desde a década de setenta tem percebido um crescente número de criação de holdings familiares pelos aspectos que serão mostrados ao longo do trabalho. A pesquisa utilizou fontes secundárias para obter os dados para a análise (consulta a sites, jornais e revistas, pesquisas de empresas formadas por holdings). Um estudo (citado a seguir em detalhes) mostra ao longo dos últimos cinquenta anos, o cenário jurídico brasileiro tem percebido um aumento na abertura de empresas com o caráter de holding. Mas os motivos que capturam todas as sinergias existentes são objetos de estudos desse trabalho. Isso se deve, em parte, a fuga dos trâmites burocráticos e onerosos de processos de inventários, segurança e assertividade na divisão de heranças (cada beneficiário com a sua cota previamente), gerando economia com custas advocatícias e eficácia na integração. Integrar essas decisões a uma eficiente administração talvez seja o principal desafio para empresas que participam desses processos cada vez mais comuns no capitalismo mundial. No Brasil, onde o crescimento do nascimento desse tipo de empresa tem sido mais recente, operações como estas têm se tornado mais comuns, e as empresas envolvidas estão construindo o seu aprendizado sobre as principais ferramentas que podem (e devem) ser utilizadas para não cometer o erro de levar em conta apenas valores tangíveis das operações, como sinergias, custos, retornos, etc. As conclusões deste trabalho apontam para uma contribuição efetiva do entendimento aos reais motivos que levam à abertura de holdings familiares, em especial no item "jurisprudência". A atividade jurídica ajuda a azeitar estas relações, abordando e discutindo as causas e propondo uma reflexão sobre o tema.

Palavra-chave: Holding, abertura de empresas, inventário

\section{FAMILY HOLDING}

\begin{abstract}
The objective of this study was to evaluate, in the light of legal doctrine, how a family holding company influences the course of a division of quotas in companies as a form of anticipation and hereditary security. For methodological reasons, this study will focus on the Brazilian legal sector, which since the seventies has seen an increasing number of family holdings created by the aspects that will be shown throughout the work. The research used secondary sources to obtain the data for the analysis (consult sites, newspapers and magazines, surveys of companies formed by holdings). A study (cited in detail below) shows over the last fifty years, the Brazilian legal scenario has seen an increase in the opening of companies with the holding character. But the motives that capture all the existing synergies are objects of study of this work. This is due, in part, to the avoidance of bureaucratic and costly procedures for inventories, security and assertiveness in the inheritance division (each beneficiary with its quota previously), generating savings with legal
\end{abstract}


costs and efficiency in integration. Integrating these decisions into an efficient administration may be the main challenge for companies that participate in these increasingly common processes in world capitalism. In Brazil, where birth growth of this type of company has been more recent, operations like these have become more common, and the companies involved are building their learning about the main tools that can (and should) be used not to commit the error of taking into account only tangible values of operations, such as synergies, costs, returns, etc. The conclusions of this work point to an effective contribution of the understanding to the real motives that lead to the opening of family holdings, especially in the item "jurisprudence". Legal activity helps to oil these relationships by addressing and discussing the causes and proposing a reflection on the subject.

Keywords: Holdings, opening of companies, inventory 


\section{INTRODUÇÃO}

Holding é uma empresa que possui como atividade principal a participação acionária majoritária em uma ou mais empresas.

Por se tratar de uma palavra da língua estrangeira, sua tradução sugere, dentre outras, as seguintes palavras: “ter, segurar, prender, reter, guardar, fazer realizar, defender..." É esse o objeto da holding, proporcionar uma longevidade e solidificação do patrimônio.

Por oportuno, vale destacar que o uma holding familiar constitui uma forma preventiva e econômica de se realizar a antecipação de herança, pois o controlador poderá doar aos seus herdeiros as cotas partes da companhia gravando-as com cláusula de usufruto vitalício em favor do doador, assim como de impenhorabilidade, de incomunicabilidade, de inalienabilidade e reversão.

É corriqueiro no dia a dia, escutar a expressão: "sociedade e família não combinam! ". Contudo, a holding familiar é um instrumento preocupado com a gestão dos conflitos ligados a sucessão, bem como, uma maneira de preparar os sucessores para o controle dos bens. Imagine a situação hipotética, de uma determinada pessoa receber uma fábrica ou uma fazenda após um falecimento de seu ascendente, sendo que o mesmo não devidamente preparado para estar no controle destas, certamente estaria o negócio fadado ao insucesso.

É aí que "entra em cena" a ideia da criação da holding. Mamede e Mamede (2017, p. 196), afirmam que "A principal virtude de uma empresa poderia ser justamente sua condição de organização familiar. Erram aqueles que consideram isso um defeito".

Sua fundação não estaria apenas preocupada nos aspectos jurídicos, tributários e econômicos, mas sim, num contexto social que visa à harmonia familiar e continuação dos negócios, conforme estudaremos nos próximos capítulos.

\section{METODOLOGIA}

O método utilizado no presente trabalho é pesquisa a legislação, decisões judiciais, bem como, nas doutrinas relevantes na matéria objeto de estudo.

\section{CONCEITO DE HOLDING}

Holding tem por finalidade a criação de uma pessoa jurídica que terá como controlar outras empresas e negócios de um determinado grupo de pessoas ou empresas, sendo uma companhia cujo objetivo principal é manter outras companhias.

Atualmente os empresários e pessoas jurídicas têm tido um novo olhar para a criação da Holding, especialmente pelas vantagens de sua criação, pois além de uma estrutura organizada, é feito o planejamento societário, sendo que os bens serão organizados de forma adequada, e ainda, um ponto extremamente relevante a vantagem tributária, especialmente pelo Brasil ser uma país onde existe uma alta carga tributária.

Lodi e Lodi (2011, p. 33), afirmam que

a holding tem como as principais funções a finalidade de manter majoritariamente as ações de outras empresas que visam o controle e a concentração de grupos empresarias; o poder de controle que é um acordo societário, com número de cotas e qualidade suficientes para influenciar nas decisões; o caráter de internacionalidade é que as empresas controladas pela holding não precisam necessariamente estar no mesmo pais, entre outros aspectos.

Assim, a Holding tem como objetivo controlar as atividades das empresas que fazem parte do seu capital social. Ela não tempo, a título de exemplo, a função de vender determinado produto ou serviço, não é aberta ao público, ou ainda, tem seu lucro pautado em suas relações comerciais, mas sim o seu êxito dependerá do funcionamos das empresas controladas. 


\section{MOTIVOS PARA CRIAÇÃO DA HOLDING}

São muitos os aspectos positivos para se fundar uma holding, entretanto, podemos pontuar que após sua criação, os problemas que assolação o direito civil no mundo inteiro no ramo familiar, (leia-se sucessões, divórcios e dissolução de sociedade de união estável) estariam mitigados, pois após sua estruturação, tanto a sucessão, bem como, desfazimento de sociedades conjugais estariam previamente organizados.

É válido salientar, que com a fundação da holding haverá um planejamento estratégico, possibilitando a aquisição de empréstimos e financiamentos, poderá expandir os negócios, aumentando consideravelmente o poder de barganha com as instituições de créditos, especialmente com concessão de taxas de juros mais baixas.

Lodi e Lodi (2011, p. 11), contribuem ainda que, com a reaplicação dos lucros, seja ela de maneira total ou parcial, também é uma finidade de sua criação. Ademais, entre os diversos pontos positivos quando se falamos em sua fundação, devemos salientar a questão de se organizar e estruturar o patrimônio, seja ele familiar ou empresário.

\section{ASPECTOS NEGATIVOS CRIAÇÃO DA HOLDING}

Conforme o supracitado, a holding tem por finalidade o planejamento sucessório e a organizações das empresas.

O que se recomenda é que, quando da conferência das participações detidas pelo indivíduo na operacional para a holding, que sejam analisadas as possibilidades de aproveitamento de aumento de custo do investimento, de medidas societárias visando maior eficiência fiscal, diminuição do deságio, preservação da política de distribuição de dividendos, e utilização do instituto do usufruto.

Alternativas à constituição de holding são a criação de classes de ações e o fundo de investimento em participações.

Não atendidos esses cuidados, a holding de participações pode colocar em risco vantagens já existentes ou implicar um aumento da carga fiscal, passando de solução de problema a um problema de difícil solução.

\section{PLANEJAMENTO SUCESSÓRIO}

É público e o notório, que a palavra inventário e partilha os remete a algo custos, burocracia e morosidade. Quando temos um evento morte, que é natural da existência humana existe praticamente duas situações: a primeira é que o de cujus enfrentou um longo processo de saúde, tendo muitas vezes disposto ele e sua família de um alto custo de tratamento médico, pois sabemos que no Brasil o Sistema Único de Saúde - SUS é uma instituição falida, de uma grande quantia para custear o seu tratamento; e, a segunda situação, trata-se dos falecimentos repentinos, sejam eles por acontecimentos a saúde ou por acidentes domésticos, automobilísticos, aéreos, dentre outros.

É claro que na maioria das situações, dificilmente a viúva e herdeiros estão preparados psicologicamente para enfrentar a burocracia de um inventário, e ainda, para; suportar os altos custos de advogado, custas processuais ou extrajudiciais, na verdade o que ocorre é uma degradação emocional e financeiro.

Nesse pensamento Mamede e Mamede (2017), conceituam:

Não se pode deixar de considerar o custo elevado da ausência de um plano sucessório e, mesmo, da preparação das pessoas que venham eventualmente ocupar a administração societária a bem da proteção dos interesses familiares. Em outras lavras, repetindo o já faziam nossos antepassados, há séculos é preciso formar sucessores. Corajosamente, é indispensável preparar a família para a sucessão, ainda que implique em trabalhar com a ideia da própria morte. São o que sempre fizeram ao longo da história da humanidade, os grandes homens e mulheres que, assim, protegeram suas famílias, suas comunidades, suas empresas, e, alguns casos, seu povo e seu estado. A lista de exemplos é larga. 
Outro ponto relevante é o curto prazo previsto para dar início e se recolher o imposto causa mortis. O atual código civil prevê: "Art. 611. O processo de inventário e de partilha deve ser instaurado dentro de 2 (dois) meses, a contar da abertura da sucessão, ultimando-se nos 12 (doze) meses subsequentes, podendo o juiz prorrogar esses prazos, de ofício ou a requerimento de parte". O prazo para início é geralmente cumprido, entretanto, devido à burocracia e custo, o prazo para se finalizar se alongar por anos e anos.

Conforme indica o art. 155, I, Constituição da República, os Estados e o Distrito Federal podem instituir tributo sobre heranças, com incidência sobre transmissão de direitos, bens móveis e imóveis. Seguindo tal disposição legal, vigente Código Tributário Nacional, disciplina o imposto nos artigos 35 a 42, entretanto, deve ser levado em conta a Constituição, pois texto legal do Código Tributário trata apenas de um imposto de transmissão de competência estadual, referindose apenas sobre transmissão de bens imóveis e de direitos a eles relativos.

Exemplificando, no Estado de São Paulo, a Lei Estadual n.o 10.705 de 28 de dezembro de 2000, dispõem sobre o Imposto sobre Transmissão Causa Mortis e Doação de Quaisquer Bens ou Direitos - ITCMD, aplicando se alíquota de quatro por cento (4\%), tanto nos casos de sucessão e doação, com previsão de isenções em alguns casos de pequeno patrimônio, sendo previsto no artigo 16, da referida Lei“ - O imposto é calculado aplicando-se a alíquota de quatro por cento (4\%) sobre o valor fixado para a base de cálculo".

No Estado de Santa Catarina, a situação é ainda mais onerosa, pois a alíquota do imposto causa mortis e doação para patrimônio acima de $\mathrm{R} \$ 150.000,00$ (cento e cinquenta mil reais) é de oito por cento (8\%), e o caso de não pagamento poderá ocorrer uma multa de até cinquenta por cento $(50 \%)$ do valor devido.

Destarte, ainda é obrigatória a participação do advogado na realização dos inventários, pois conforme preceito constitucional sua atividade é inerente cumprimento da administração da justiça.

\section{CONCLUSÃO}

Diante de todo o exposto pelo presente trabalho, é possível concluir a importância de um planejamento sucessório e estratégico organizado pela holding, especialmente a familiar.

No Brasil, é público e notório que enfrentamos o dissabor de uma elevada carga tributária, pagamos impostos com os lucros obtidos durante todo percurso de nossa vida, e quando partimos nossos herdeiros deverão, infelizmente, continuando essa jornada ao custear o imposto causa mortis.

Mas não podemos levar em conta apenas os aspectos financeiros ligados à sucessão, mas também a importância de se manter a harmonia entre as famílias, afinal, a família ainda é a base que norteia os bons costumes, o caráter, honestidade, dentre outros fatores positivos que a sociedade aprova.

Importante destacar, que com o planejamento sucessório, e por que não dizer estratégico dos negócios da família, fundada a holding estariam mitigadas eventuais frustações advindas dos divórcios ou dissoluções de união estável, que poderiam colocar em risco todo o planejamento da herança antecipada pelos pais.

Ademais, podemos concluir que cada vez mais, como nos demais ramos do nosso ordenamento jurídico, é sempre melhor evitar lides, privilegiar entidade familiar, tendo em mente a melhor solução para um planejamento de herança é a holding, evitando, deste modo, os percalços do cotidiano da feitura de um inventário.

Por fim, acredito que em outro momento, seria importante a complementação da pesquisa, no que diz respeito à aplicação do imposto de renda, e também da modalidade de holding empresarial. 


\section{REFERÊNCIAS}

BAGNOLI, Martha Gallardo Sala. Holding imobiliária como planejamento sucessório. São Paulo: Quartei Latin, 2016.

BRASIL, República Federativa do. Dispõe Constituição Federal. Disponível em http://www.planalto.gov.br/ccivil_03/constituicao/constituicao.htm. Acesso dia 14 abr. 2018.

BRASIL, República Federativa do. Legislação Tributaria. Dispõe sobre a instituição do Imposto sobre Transmissão "Causa Mortis" e Doação de Quaisquer Bens ou Direitos - ITCMD. Disponível em

http://info.fazenda.sp.gov.br/NXT/gateway.dll/legislacao_tributaria/leis/lei10705.htm?f=template s\&fn=default.htm\&\&vid=sefaz_tributaria:vtribut. Acesso dia 14 abr. 2018.

BRASIL, República Federativa do. Lei no 11.441, de 4 de janeiro de 2007. Dispõe Código de Processo Civil Disponível em http://www.planalto.gov.br/ccivil_03/_ato20072010/2007/lei/l11441.htm. Acesso dia 14 abr. 2018.

BRASIL, República Federativa do. Lei no 13.105, de 16 de março de 2015. Dispõe Código de Processo Civil. Disponível em http://www.planalto.gov.br/ccivil_03/_ato20152018/2015/lei//13105.htm. Acesso dia 14 abr. 2018.

BRASIL, República Federativa do. Lei no 10.406, de 10 de janeiro de 2002. Dispõe Institui o Código Civil. Disponível em http://www.planalto.gov.br/ccivil_03/leis/2002/l10406.htm. Acesso dia 14 abr. 2018.

BRASIL, República Federativa do. Lei no 5.172, de 25 de outubro de 1966. Dispõe sobre o Sistema Tributário Nacional e institui normas gerais de direito tributário aplicáveis à União, Estados e Municípios. Disponível em http://www.planalto.gov.br/ccivil_03.htm. Acesso dia 14 abr. 2018.

BRASIL, Ordem dos Advogados. Dispõe Tabela de Honorários. Disponível em http://www.oabsp.org.br/servicos/tabela-de-honorarios. Acesso dia 14 abr. 2018.

FAZENDA, Secretaria de Estado da. Dispõe Legislação Tributaria. Disponível em http://www.sef.sc.gov.br. Acesso dia 14 abr. 2018. 